\title{
High-throughput profiling of diapause regulated genes from Trichogramma dendrolimi (Hymenoptera: Trichogrammatidae)
}

\author{
Xue Zhang ${ }^{1}$, Wenmei Du', Junjie Zhang ${ }^{1}$, Zhen Zou ${ }^{2}$ and Changchun Ruan ${ }^{1 *}$
}

\begin{abstract}
Background: The parasitoid wasp, Trichogramma dendrolimi, can enter diapause at the prepupal stage. Thus, diapause is an efficient preservation method during the mass production of $T$. dendrolimi. Previous studies on diapause have mainly focused on ecological characteristics, so the molecular basis of diapause in $T$. dendrolimi is unknown. We compared transcriptomes of diapause and non-diapause T. dendrolimi to identify key genes and pathways involved in diapause development.

Results: Transcriptome sequencing was performed on diapause prepupae, pupae after diapause, non-diapause prepupae, and pupae. Analysis yielded a total of 87,022 transcripts with an average length of $1604 \mathrm{bp}$. By removing redundant sequences and those without significant BLAST hits, a non-redundant dataset was generated, containing 7593 sequences with an average length of 3351 bp. Among them, 5702 genes were differentially expressed. The result of Gene Ontology (GO) enrichment analysis revealed that regulation of transcription, DNA-templated, oxidation-reduction process, and signal transduction were significantly affected. Ten genes were selected for validation using quantitative real-time PCR (qPCR). The changes showed the same trend as between the qPCR and RNA-Seq results. Several genes were identified as involved in diapause, including ribosomal proteins, zinc finger proteins, homeobox proteins, forkhead box proteins, UDP-glucuronosyltransferase, Glutathione-S-transferase, p53, and DNA damage-regulated gene 1 (pdrg1). Genes related to lipid metabolism were also included.
\end{abstract}

Conclusions: We generated a large amount of transcriptome data from T. dendrolimi, providing a resource for future gene function research. The diapause-related genes identified help reveal the molecular mechanisms of diapause, in T. dendrolimi, and other insect species.

Keywords: Trichogramma dendrolimi, Transcriptome, RNA-Seq, Diapause, Diapause-related genes

\footnotetext{
* Correspondence: ruanchangchun@126.com

${ }^{1}$ Engineering Research Center of Natural Enemies, Institute of Biological

Control, Jilin Agricultural University, Changchun 130118, China

Full list of author information is available at the end of the article
}

(c) The Author(s). 2020 Open Access This article is licensed under a Creative Commons Attribution 4.0 International License, which permits use, sharing, adaptation, distribution and reproduction in any medium or format, as long as you give appropriate credit to the original author(s) and the source, provide a link to the Creative Commons licence, and indicate if changes were made. The images or other third party material in this article are included in the article's Creative Commons licence, unless indicated otherwise in a credit line to the material. If material is not included in the article's Creative Commons licence and your intended use is not permitted by statutory regulation or exceeds the permitted use, you will need to obtain permission directly from the copyright holder. To view a copy of this licence, visit http://creativecommons.org/licenses/by/4.0/. The Creative Commons Public Domain Dedication waiver (http://creativecommons.org/publicdomain/zero/1.0/) applies to the data made available in this article, unless otherwise stated in a credit line to the data. 


\section{Background}

The insect egg parasitoid, Trichogramma dendrolimi Matsumura (Hymenoptera: Trichogrammatidae), is used as a biological control agent against several important Lepidopteran insect pests, such as Chilo suppressalis [1], Cnaphalocrocis medinalis [2], and Ostrinia furnacalis [3]. Application of $T$. dendrolimi is usually involves inundative release into fields, so large numbers of $T$. dendrolimi are needed in biological control programs. Preservation of parasitoids to assure their supply is essential for the continuous production of parasitoids throughout the year [4]. Cold storage of parasitized host eggs is the most commonly used method for parasitoid preservation [5]. Although Trichogramma can be kept for a long period at low temperatures, their performance, such as emergence rate and longevity, decreases as storage time increases. For example, the survival rate of $T$. dendrolimi significantly decreases after 3 weeks of storage at low temperatures [6], and similar decreases have been found in other Trichogramma species $[7,8]$. Therefore, it is important to improve the effectiveness of preservation. Diapause can be an effective mechanism to solve this problem.

Diapause is an essential processes that helps insects avoid periods that are unfavorable for growth and development [9]. Insects can utilize diapause to resist adverse environmental conditions. When future environmental conditions likely become unsuitable, diapause may be initiated to reduce energy and metabolic activity, enhance stress resistance, and extend lifespan [10-12]. Many aspects of diapause have been comprehensively reviewed in insects, and these show that diapause is a complicated process [13-15]. Some studies have focused on optimized conditions for diapause induction or termination to improve biological control programs [16-20]. Several diapause-associated genes, such as dilp1, forkhead box protein $\mathrm{O}$ (foxo), and $a k t$, have been identified in insect species [21-26]. Few studies, however, have examined the molecular mechanism of diapause in Trichogramma spp. Many phenomena related to diapause in $T$. dendrolimi are unexplained. For example, adults of $T$. dendrolimi that have experienced diapause development produce more eggs [27]. Therefore, it is necessary to better understand the diapause mechanism. Transcriptome sequencing is useful for gene expression research, and many studies have used RNA-sequencing (RNA-Seq) to address a variety of problems. Some studies have focused on insect resistance to insecticides [28-31]. Other studies have examined insect adaptability to extreme environments $[32,33]$, or focus on selected areas of the genome such as chemosensory genes [34]. There are few studies on insect diapause using RNA-Seq, but Hao et al. (2019) identified the candidate genes (rail and foxo) related to the FOXO pathway in the egg diapause regulation of Locusta migratoria [35].
The objective of this study was to use RNA-Seq to characterize diapause-related genes in T. dendrolimi. We report the gene expression profiles of diapause and nondiapause $T$. dendrolimi. The results of this study are expected to provide a reference for deciphering the diapause mechanism in $T$. dendrolimi and guiding the use of $T$. dendrolimi in biological control programs.

\section{Results \\ Diapause induction, termination, sequencing, and gene identification}

After the completion of the diapause induction process, the parasitized host eggs were dissected to verify whether T. dendrolimi entered diapause successfully. Diapausing parasitoids remain at the prepupal stage (Dpre). If diapause induction fails, the prepupae would die or continue to develop into pupae and adults. Following the diapause termination process, the parasitized host eggs were transferred to normal development conditions $\left(26^{\circ} \mathrm{C} \pm 1{ }^{\circ} \mathrm{C}\right.$, $60 \% \pm 5 \% \mathrm{RH}, 16: 8 \mathrm{~h} \mathrm{~L}: \mathrm{D})$. If diapause was disrupted, the parasitoids would transform from prepupa to pupa within several days, noted as Dp. However, if diapause was not disrupted, the $T$. dendrolimi would remain in the prepupa stage. In this study, 99\% of the parasitoids entered diapause successfully, and about $95 \%$ resumed development after the $70 \mathrm{~d}$ termination treatment. The prepupae and pupae of $T$. dendrolimi that developed under normal conditions were obtained as reference groups noted as NDpre and NDp, respectively.

RNA samples obtained from distinct stages of $T$. dendrolimi were prepared and sequenced using the Illumina Hiseq2000 sequencing platform. Four cDNA libraries were constructed from the samples of Dpre, Dp, NDpre, and NDp. After filtering raw reads (reads containing adaptors, reads containing $\mathrm{N}$ larger than $10 \%$, and lowquality reads (Qphred <20) were removed), clean reads were retained (Table 1 ). The clean data were assembled by Trinity and Corset with 87,022 transcripts, and an average length of $1604 \mathrm{nt}$ and an N50 of 3148. Of the transcripts, 35,231 (40.5\%) were longer than $1000 \mathrm{bp}$ (Table 2).

To study gene function, transcripts were annotated using BLASTX searches against the non-redundant (NR) sequence database; 39,969 (45.92\%) displayed homology to known proteins $\left(\mathrm{E}<1 \mathrm{e}^{-5} ;\right.$ Fig. 1a). Nearly 25,000 annotated transcripts, over $65 \%$ of the annotated transcripts, were homologous to $T$. pretiosum, probably because the genome of $T$. pretiosum was the only available Trichogramma. Fewer transcripts were homologous to Nasonia vitripennis (1217, 3.1\%), Apis florea $(26,0.03 \%)$, A. dorsata $(12,0.01 \%)$, or A. cerana (15, 0.01\%) (Fig. 1b). Fewer than 40 transcripts matched those from Microplitis demolitor. Among all annotated transcripts, $73.0 \%$ had significant homology 
Table 1 Summary of Illumina transcriptome assembly for T. dendrolimi

\begin{tabular}{llllllll}
\hline Sample name & Raw reads & Clean reads & Clean bases & Error rate (\%) & Q20 (\%) & Q30 (\%) & GC content (\%) \\
\hline Dpre-A & $49,071,974$ & $47,695,622$ & $7.15 G$ & 0.03 & 96.52 & 91.43 & 41.30 \\
Dpre-B & $49,810,990$ & $47,210,830$ & $7.08 G$ & 0.01 & 97.26 & 93.17 & 43.77 \\
Dpre-C & $47,347,676$ & $44,732,274$ & $6.71 G$ & 0.01 & 97.29 & 93.25 & 43.84 \\
Dp-A & $49,517,974$ & $48,189,484$ & $7.23 G$ & 0.02 & 95.98 & 90.34 & 41.11 \\
Dp-B & $51,270,660$ & $48,977,252$ & $7.35 G$ & 0.02 & 96.97 & 92.69 & 40.74 \\
Dp-C & $45,943,884$ & $43,816,628$ & $6.57 G$ & 0.02 & 96.84 & 92.38 & 42.41 \\
NDpre-A & $45,701,770$ & $44,515,808$ & $6.68 G$ & 0.01 & 96.28 & 90.97 & 40.07 \\
NDpre-B & $50,860,900$ & $48,522,830$ & $7.28 G$ & 0.01 & 97.37 & 93.48 & 41.57 \\
NDpre-C & $47,589,266$ & $45,544,062$ & $6.83 G$ & 0.01 & 97.36 & 93.45 & 38.73 \\
NDp-A & $56,029,606$ & $54,463,466$ & $8.17 G$ & 0.01 & 96.88 & 92.35 & 38.69 \\
NDp-B & $46,605,166$ & $44,410,060$ & $6.66 G$ & 0.01 & 97.19 & 93.11 & 40.63 \\
NDp-C & $62,287,702$ & $59,900,798$ & $8.99 G$ & 0.01 & 97.24 & 93.26 & 40.71 \\
\hline
\end{tabular}

Note: $A, B$, and $C$ represent the three biological replicates of each sample

with an E-value of $<10^{-30}$ (Fig. 1c), and $52.3 \%$ had a similarity greater than $80.0 \%$ (Fig. 1d). After filtering and removing redundant sequences, we retained those with significant BLAST hits and constructed a nonredundant dataset containing 7593 unigenes with an average length of $3351 \mathrm{nt}$. Based on the annotation, such as gene length, ID, and speculative function, the diapause-related genes and potential genes involved in diapause were sorted out for further analysis.

\section{Identification of DEGs and functional classification}

Ten genes were selected for validation with qPCR, and glyceraldehyde phosphate dehydrogenase $(G A P D H)$ was selected as the reference gene after measuring its stable expression level in diapause and non-diapause groups. The tendencies of the expression profiles of these genes were similar according to RNA-Seq and qPCR (Fig. 2).

Table 2 General features of the de novo assembled transcriptome by Trinity

\begin{tabular}{lll}
\hline & Transcripts & Unigenes \\
\hline 200-500 bp & 131,509 & 22,869 \\
$500-1 \mathrm{kbp}$ & 42,525 & 28,922 \\
$1 \mathrm{k}-2 \mathrm{kbp}$ & 18,308 & 18,119 \\
>2 kbp & 17,115 & 17,112 \\
Total & 209,457 & 87,022 \\
Min length & 201 & 201 \\
Mean length & 865 & 1604 \\
Median length & 389 & 814 \\
Max length & 29,327 & 29,327 \\
N50 & 1732 & 3148 \\
N90 & 308 & 647 \\
Total nucleotides & $181,250,941$ & $139,571,319$ \\
\hline
\end{tabular}

Among these 10 selected genes, all except trehalase (tre) were up-regulated during diapause.

To study diapause-specific transcriptional changes in $T$. dendrolimi induced by low temperature, we made pairwise comparisons between different libraries to identify the DEGs. A total of 5702 DEGs were identified among four groups. Among these DEGs, there were 3182 DEGs changed in Dpre compared to NDpre. DESeq identified 3251 and 3442 DEGs exclusively changed in Dp vs NDp and Dpre vs Dp, respectively. In addition, the DEGs changed in NDpre vs NDp were 1511. This group of DEGs may be the genes related to normal development, namely from prepupa to pupa, not to diapause development. According to the Venn diagram, there were 463 genes changed throughout the diapause development process, while in the normal development process, the expression of these genes did not change (Fig. 3).

To determine the potential function of identified DEGs, GO enrichment was performed. In all combinations, except for Dpre vs $\mathrm{Dp}$, more genes were upregulated. However, when we compared Dpre to Dp, there was little difference in the number of up- and down-regulated genes. Furthermore, more DEGs were assigned to the same category among different groups. Regulation of transcription, DNA-templated process, oxidation-reduction process, and signal transduction process were the top three in these four groups. The number of DEGs involved in ribosome biogenesis was much higher during diapause development than during normal development (Fig. 4). The subsequent analyses are based directly upon these results.

\section{Comparative analysis of genes involved in diapause}

Based on the results of GO enrichment, we focused on the genes enriched in the oxidation-reduction process, 


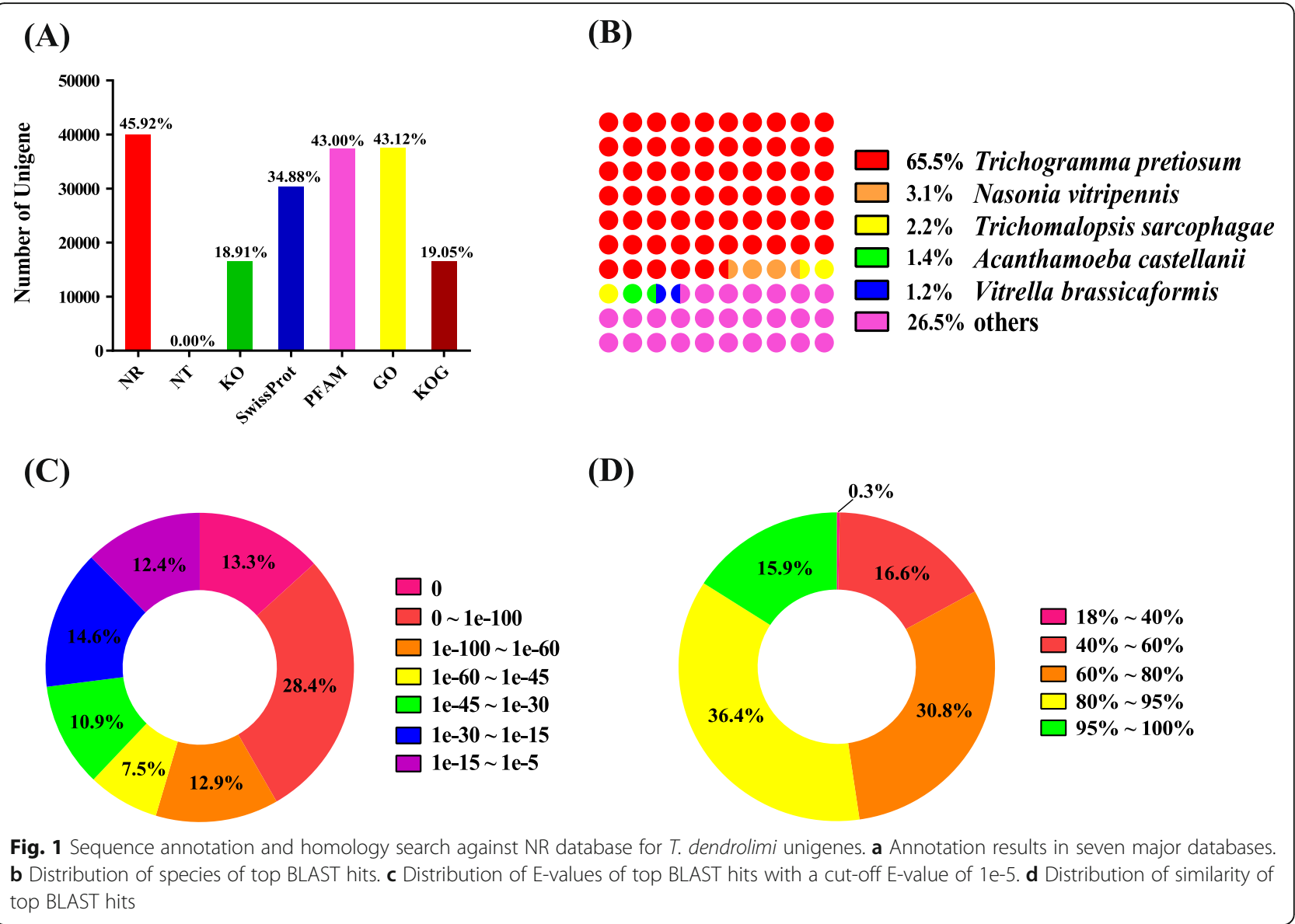

\section{Diapause Non-diapause}

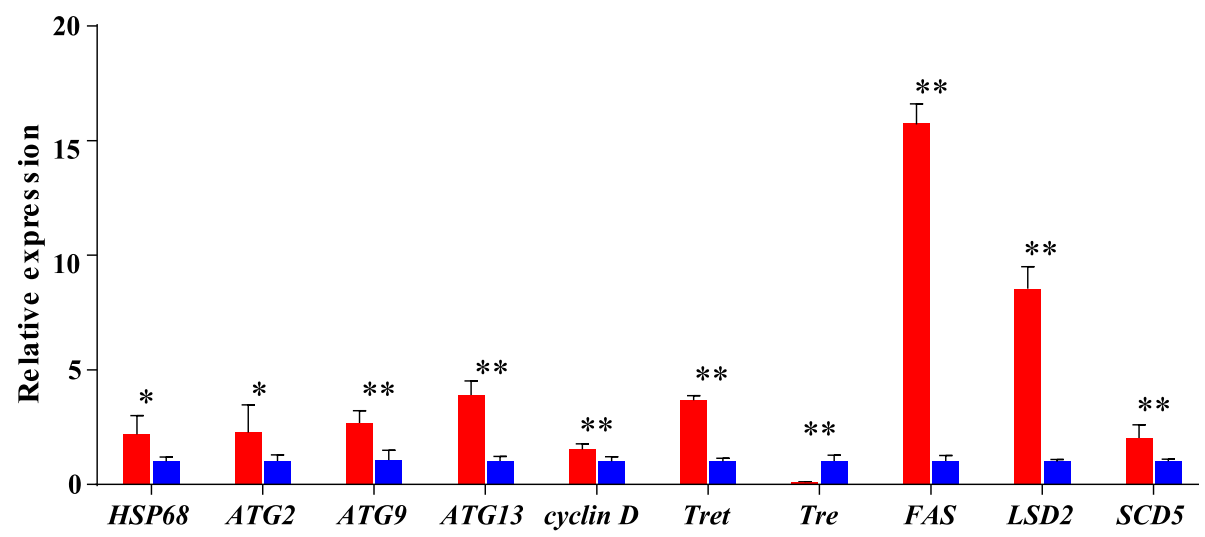

Fig. 2 Relative expressions of 10 selected genes analyzed by qPCR analysis. Nine genes were up-regulated, and one gene was down-regulated during the diapause stage. The changing trends of all 10 genes between diapause and non-diapause were identical between qPCR and RNA-Seq. The red bar represents the diapause, while the blue bar represents the non-diapause. The relative mRNA levels are represented as the mean \pm S.D. ${ }^{*}, p<0.05 ;{ }^{* *}, p<0.01$ 

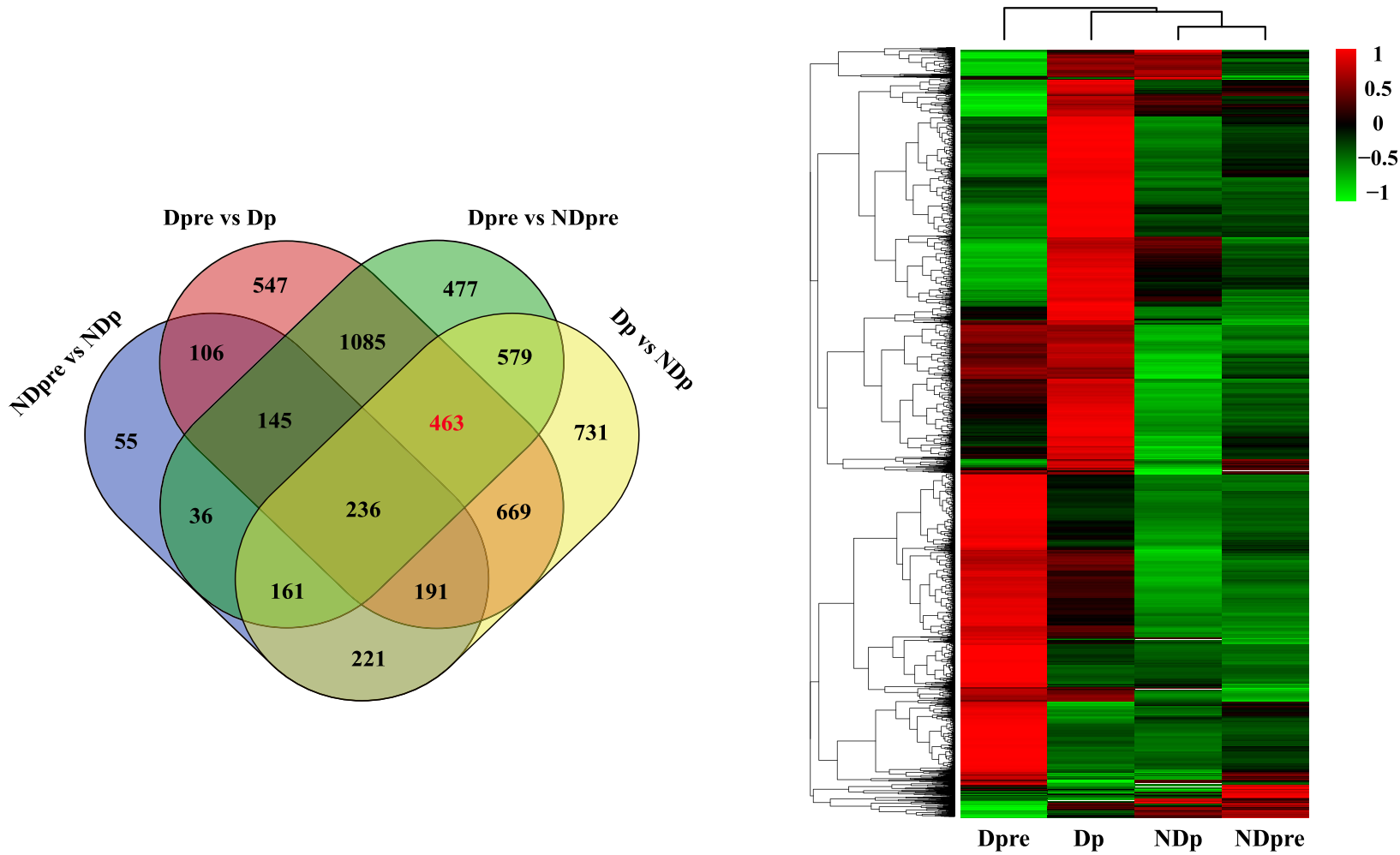

Fig. 3 Venn graph and heatmap of DEGs across the four treatments. In the heatmap graph, red indicates relatively high expression, green indicates relatively low expression, and black represents moderate expression

regulation of transcription, DNA-templated process and signal transduction process, which were processes enriched in most DEGs. In addition, we also examined ribosome biogenesis.

A total of 342 genes were identified in the oxidationreduction process, and 16 of these belong to cytochrome P450s (CYP450s). In the T. dendrolimi transcriptome, 22 CYP450s were identified, and 16 were differentially expressed. These 16 genes belonged to 4 clans. In diapause stages (Dpre), 10 genes were up-regulated. In the pupae after diapause (Dp), five genes were highly expressed. Only one gene (CYP9E2) was highly upregulated in normal pupae (NDp) (Fig. 5). These results show that the number of up-regulated genes during diapause was significantly higher than that in other stages.

There were 36 transcription factors differentially expressed during diapause development, and it appears that three kinds of transcription factors might be associated with diapause in $T$. dendrolimi.

The first kind is zinc finger protein. Three genes encoded zinc finger protein. Zinc finger protein 271, zinc finger 184, and zinc finger 544, were identified in the transcriptome. They were all up-regulated such that the expressions of these three genes in Dpre were higher than expression in Dp. Zinc finger protein gene 271 had an SFP domain. Genes containing this domain are putative transcriptional repressors during the G2/M (second gap period to mitotic period) transition. The weel gene, encoding an inhibitory kinase, was up-regulated during diapause in $N$. vitripennis [36]. We obtained similar results in T. dendrolimi (Fig. 6). In addition, zinc finger protein 184 contained a GDT1 domain, which is a putative $\mathrm{Ca}^{2+} / \mathrm{H}^{+}$antiporter. $\mathrm{Ca}^{2+} / \mathrm{H}^{+}$antiporter, which maintains homeostasis, has been studied in plants, but there are few studies.

The second type of transcription factor is homeobox domain protein. In the transcriptome, 11 homeoboxcontaining genes were differentially expressed during diapause except for pit1, which was significantly upregulated in the individuals that terminated diapause. Among these genes, homeobox protein homothorax (hth) had the greatest change in expression, followed by homeotic protein distal-less $(d l l)$ and homeobox protein six1 (six1). The gene expression of another homeobox protein sixl was similar to $h t h$; expression increased after entering diapause stage. And this gene may be involved in the regulation of cell proliferation, apoptosis, and embryonic development.

The third group of transcription factors is forkhead box protein. FOXOs have been identified as candidates for the molecular control of embryonic diapause in some species, like Culex pipiens [22, 37]. In T. dendrolimi, three forkhead box proteins (foxo), forkead box protein 


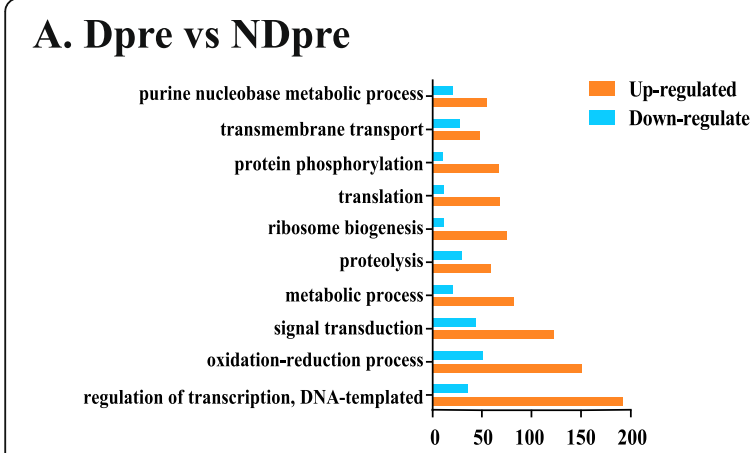

\section{Dpre vs Dp}

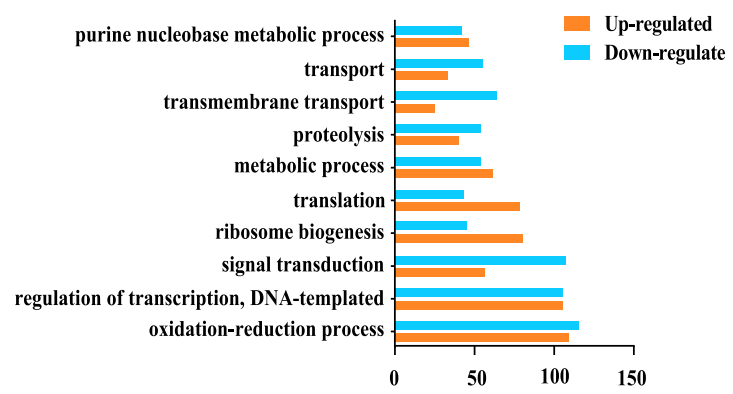

\section{B. Dp vs NDp}

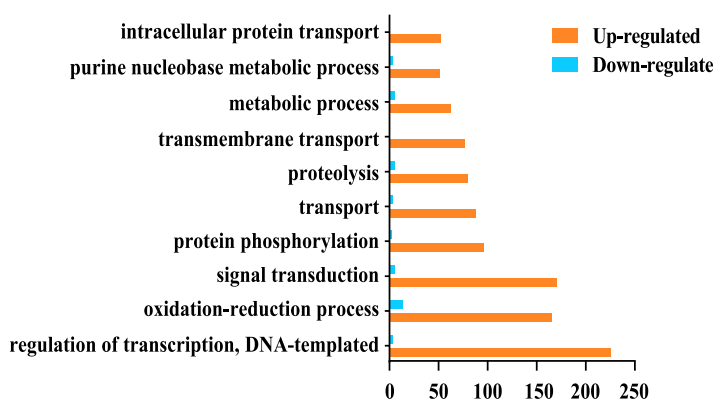

D. NDpre vs NDp

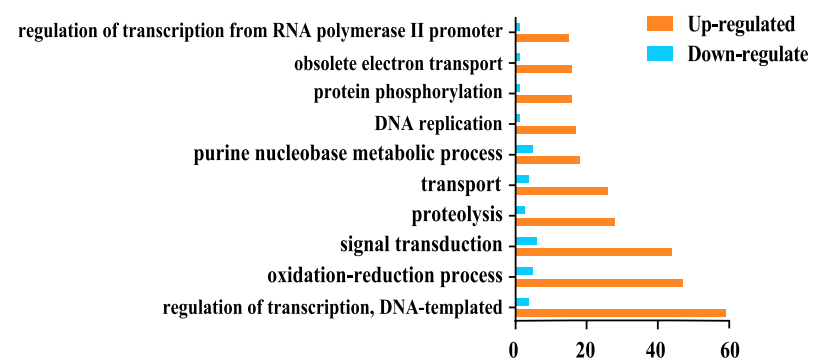

Fig. $4 \mathrm{GO}$ enrichment analysis. Ten GO items were selected according to the gene number of the four comparisons. The value of the horizontal ordinate represents the number of DEGs in each GO item. Up- or down-regulated genes are coded by different colors. a Ten GO items according to the gene number of the comparison of Dpre vs NDpre. $\mathbf{b}$ Ten GO items according to the gene number of the comparison of Dp vs NDp. $\mathbf{c}$ Ten GO items according to the gene number of the comparison of Dpre vs Dp. $\mathbf{d}$ Ten GO items according to the gene number of the comparison of NDpre vs NDp

E3 (foxe3), and forkhead box protein D3 (foxd3) were identified. These genes were up-regulated both in diapause prepupae and resulting pupae, and they likely play a role in diapause development.

In the $T$. dendrolimi transcriptome, the expression of Protein phosphatase 2A $(P P 2 A)$, which belonging to signal transduction process, was down-regulated during the diapause stage. This result was consistent with that obtained in the cotton bollworm (Helicoverpa armigera). Low $P P 2 A$ expression in diapause individuals contribute to the accumulation of $p$-Akt, and $p$-Akt leads to $H$. armigera diapause [24, 38].

In addition to these three biological processes, ribosome biogenesis is also important in the control of cell growth and division in eukaryotes [39]. In this study, ribosome biogenesis involved 31 DEGs, and 29 genes were up-regulated during prepupal diapause. Only two genes, 40S ribosomal protein S11 (rpS11) and 28S ribosomal protein S5 ( $r p S 5)$ were down-regulated during prepupal diapause. All of the $60 \mathrm{~S}$ ribosomal proteins were up-regulated (Fig. 7).

Some genes, even those not involved in the biological process, with a considerable number of genes enriched, appear to be important in the diapause development of $T$. dendrolimi, such as $p 53$ and the DNA damage-regulated gene 1 ( $p d r g 1)$, which gene expressions were significantly changed during diapause development. The transcriptional expressions of Glutathione-S-transferase (GST) and UDP-glucuronosyltransferase (UDPGT) were also upregulated during $T$. dendrolimi prepupal diapause.

Lipid metabolism is essential for energy homeostasis. Some diapausing insects use lipids for energy storage [40, 41]. During diapause, almost all selected lipid metabolism related genes were up-regulated, coinciding with the mobilization of TAG reserves (Fig. 8).

\section{Discussion}

Diapause is a dynamic process accompanied by a series of physiological transitions. Several studies have focused on the general gene expression pattern of insect diapause without a clear elucidation of the diapause mechanism. This is due to the complexity of the diapause process as well as the variations among insect species. In this study, several genes were identified related to diapause in $T$. dendrolimi. Based on the results, 16 CYP450s gene differentially expressed at different stages in T. dendrolimi. CYP450s are hemoproteins involved in physiological processes such as biosynthesis of hormones and degradation of xenobiotics [42]. There are four clans in the P450 supergene family namely CYP2, CYP3, CYP4, and Mitochondrion (Mito) [43]. The 


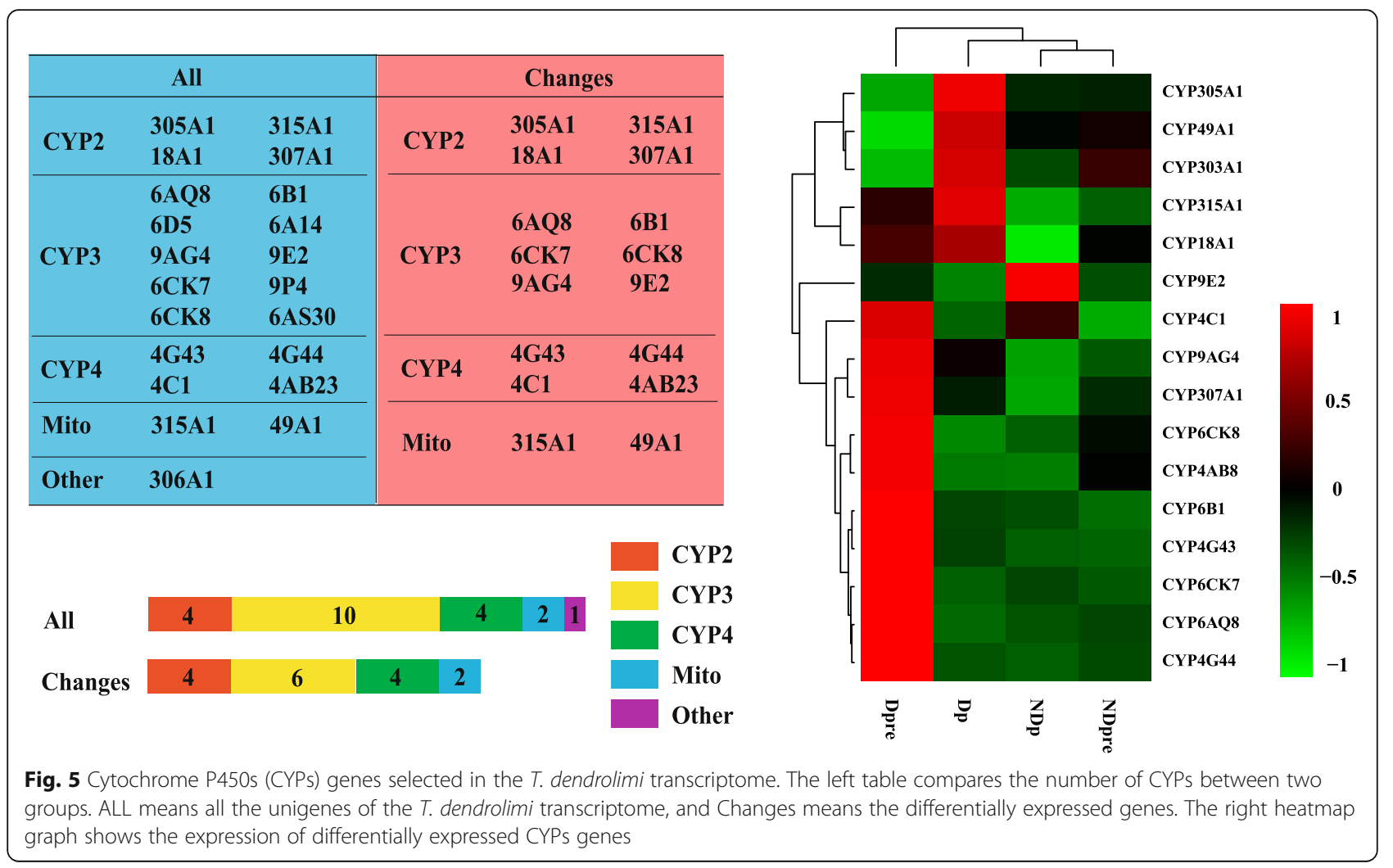

CYP450 of Schistosoma mansoni was essential for worm survival and egg development [44]. CYP4G1 is related to cuticular hydrocarbon biosynthesis in Drosophila [45]. These genes were up-regulated in diapause individuals, suggesting that when $T$. dendrolimi entered diapause, the environmental conditions are unsuitable for survival. The conditions are worse than those under normal conditions. During this process, many harmful substances may be produced. A possible function for these genes is to reduce harmful substances, and maintain cellular homeostasis.

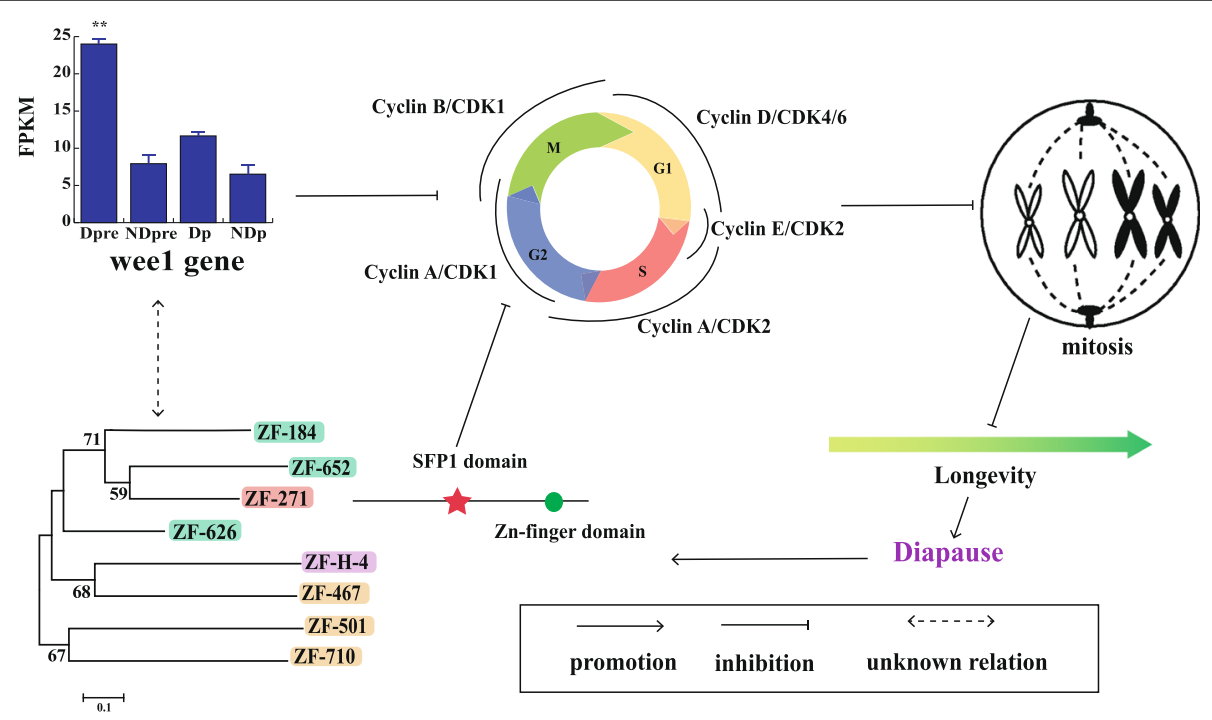

Fig. 6 Speculated pattern diagram of zinc finger protein genes in the cell cycle. Eight zinc finger protein genes were screened in this study. ZF271, indicated with a red background color, showed an interesting SFP1 domain, which is a putative transcriptional repressor regulating G2/M transition. The expression of the weel gene is also shown in the histogram. The weel gene in other species, has the ability to let the cell remain at the G2 stage 


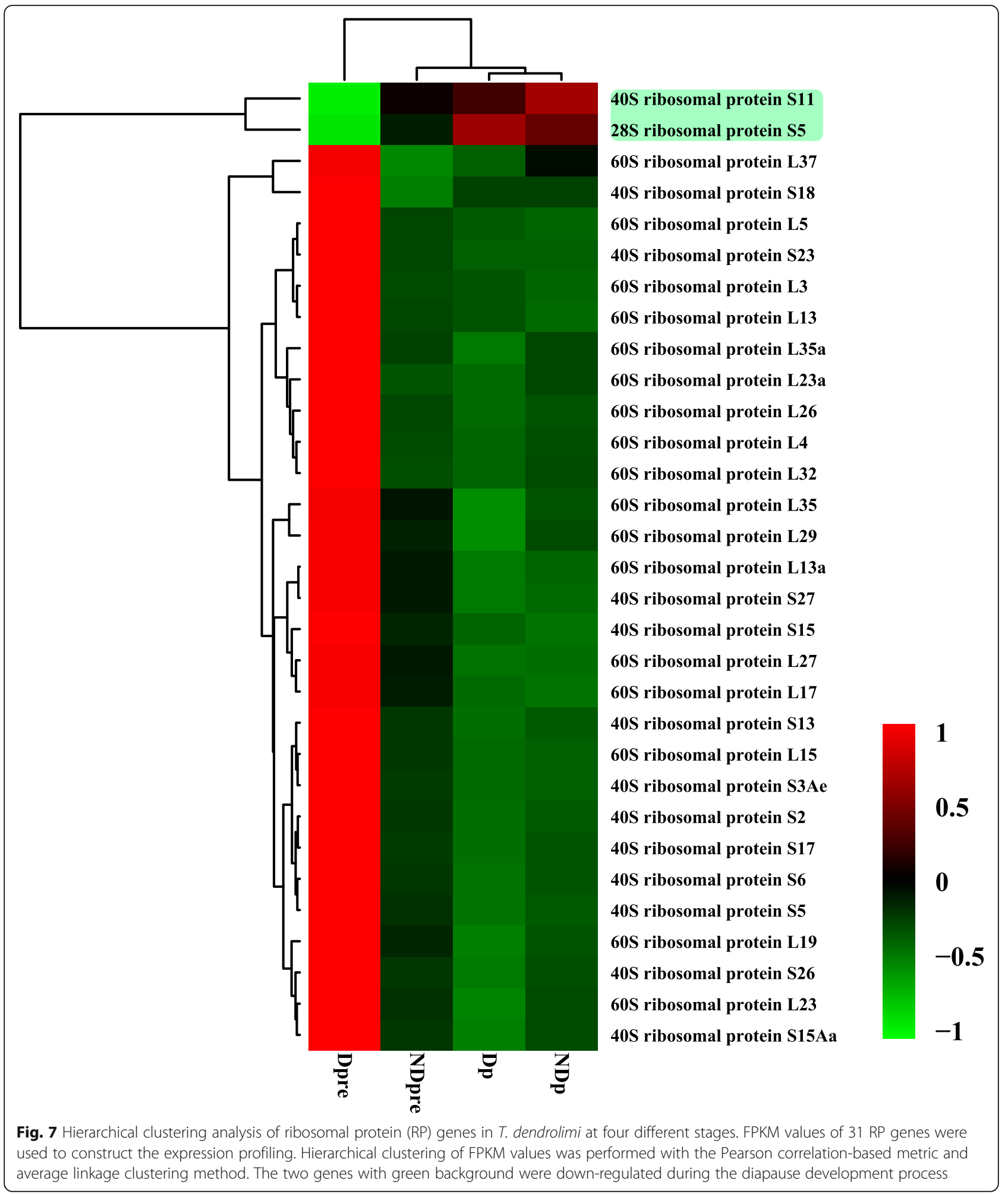

This phenomenon still occurred in pupae after diapause (Dp) compared to pupae under normal condition (NDp). These data suggest that although diapause helps insects survive adverse environments, the process can also affect insect growth. Therefore, diapause development appears to be a metabolic tradeoff required for survival.

There were three kinds of transcription factors (zinc finger protein, homeobox domain protein, and forkhead 


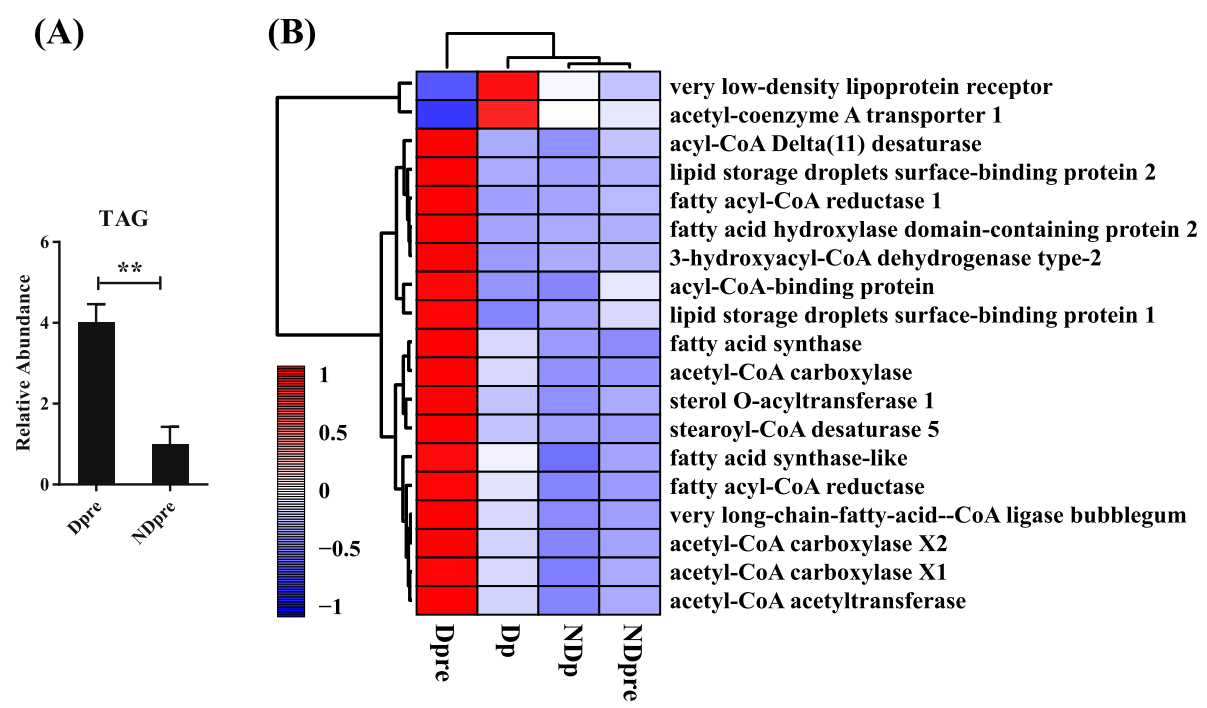

Fig. 8 Lipid metabolism changes during diapause development. a TAG was measured in diapause and non-diapause T. dendrolimi. At least three independently collected samples for each treatment were analyzed. Dpre treatments were normalized to NDpre. The error bar represents the SEM; ** $p<0.01$. b Heatmap of expression patterns of lipid metabolism-related genes with fold changes $>1$

box protein) differentially expressed during diapause development, which might be related to the diapause in $T$. dendrolimi. One of the most noticeable characteristics of diapause is the blockage of ontogeny, and this blockage always occurs with cell cycle cessation [46, 47]. In $N$. vitripennis, the $\mathrm{S}$ phase of the cell cycle disappeared in the beginning stage of diapause due to the cells being arrested in the G0/G1 (stop cell division to the first gap) and G2 phases [48]. Similarly, in the drosophilid fly, Chymomyza costata, the cell cycle of central nervous system (CNS) cells was arrested in the G0/G1 (86.6\%) and G2 (12.8\%) division phases during diapause [36]. In addition, the gene expression of wee1 was upregulated both in $T$. dendrolimi and $N$. vitripenni. Therefore, the wee1 gene might be a molecular marker of diapause in parasitoids.

During embryogenesis in Tribolium castaneum, hth involved in the segmentation process and is required for specification of body wall identities in the thorax [49]. In D. melanogaster, hth has different functions in different tissues. Hth located in the head leads to opposite effects on eye and antennal development as a negative regulator of eye development, and it acts with extradenticle (exd) to delimit the eye field and prevent inappropriate eye development [50]. Transcriptome factor dll plays a role in larval and adult appendage development [51]. In mammals, six 1 is essential for early neurogenesis in the development of olfactory epithelium [52]. They are important genes regulating myogenesis and highly up-regulated during diapause in T. dendrolimi. However, the aberrant expression of these genes may cause growth cessation. We infer that the genes that are up-regulated at diapause stage block the normal cell cycle in diapause $T$. dendrolimi.

In signal transduction, a variety of enzymes are speculated to play role in diapause. $P P 2 A$ was an interesting candidate. It is a key serine-threonine protein phosphatase, which regulates several cellular processes, including metabolism, transcription, cell cycle, autophagy, and signal transduction [53, 54]. Cell cycle withdrawal, from $G 1$ to $S$ phase, is negatively related to PP2A activity $[55,56]$. PP2A plays a multi-faceted role in the regulation of several pathways, such as the mTOR and the wnt signaling pathway, which are related to the cell cycle [53, 57]. PP2A may be involved in T. dendrolimi diapause.

In this study, we also focused the expression of genes associated with ribosome biogenesis. The rate of ribosome synthesis during diapause was lower than that of non-diapause eggs in Bombyx mori, so the up-regulation of ribosomal proteins can play an important role in blocking diapause $[58,59]$. In C. pipiens, the expression of ribosomal protein S3a ( $r p S 3 a)$ was greatly reduced for a short time during the diapause stage. After the injection of $r p S 3 a$ dsRNA into non-diapause females, follicle development was arrested, similar to diapause state [60]. Conversely, in $T$. dendrolimi, diapause prepupae had a higher expression of ribosomal proteins compared to non-diapause wasps. However, B. mori and C. pipiens enter diapause as adults, whereas $T$. dendrolimi enters diapause as prepupae. Although diapause decreased the level of metabolism, individuals may still require energy to maintain the diapause condition. This is the first report demonstrating that ribosomal protein is related to 
diapause in $T$. dendrolimi. The specific functions of the genes involved in diapause required additional study.

Some genes, even those not involved in the biological process, with a considerable number of genes enriched, appear to be important in the diapause development of T. dendrolimi. For examples, p53 induces growth arrest or apoptosis and has a negative regulation effect on cell division by controlling an array of genes [61]. In addition, $p 53$ and $p d r g 1$ are involved in multiple cellular processes, such as apoptosis, DNA damage repair, and the cell cycle. In Artemia sinica, PDRG1 has an essential role in diapause termination and regulation of cell cycle during early embryonic development [62]. Blocking the expression of pdrg1 in human colon cancer cells significantly reduced cell growth. Transcriptome-based analysis indicated that $p 53$ expression significantly increased during diapause, and contrasting results were observed for pdrg1 in $T$. dendrolimi. This result also revealed that apoptosis activity was enhanced, although the diapause individual remained in a dormant state. It is speculated that more harmful substances were accumulated during diapause. So, it was necessary to boost apoptosis activity for wasp to survive.

UDPGT is important in the elimination of toxic xenobiotics and endogenous compounds. GST belongs to a multifunctional protein family mainly located in the cytoplasm. Both are involved in cellular detoxification. The transcriptional expressions of GST and UDPGT were upregulated during $T$. dendrolimi prepupal diapause. This was different from other species, such as the bee Tetrapedia diversipes and Tetranychus urticae in which transcripts were down-regulated during diapause [63]. In other insect species, the downregulation of GST and UDPGT might be correlated with a non-feeding condition, so the amount of exogenous substances can decrease accordingly. However, T. dendrolimi is an endoparasitoid wasp that spends its larval life within the host egg; starvation is a rare situation before the prepupae stage. Therefore, we believe that the up-regulation of these two genes in diapause $T$. dendrolimi might be due to increased resistance to unfavorable environmental conditions.

Genes related to lipid metabolism have important influence in the formation of triacylglycerol, which is the main caloric reserve during diapause. In addition, the expression of several genes significantly increased after diapause termination. This might be due to post-diapause development. Diapause $T$. dendrolimi can produce higher numbers of parasitized hosts than non-diapause $T$. dendrolimi [27]. The increased lipid storage could provide more energy for maintaining reproductive activities.

\section{Conclusions}

Diapause is an important physiological process in insects, and it has potential as a method for the long-term storage of parasitoids. Using the characteristics of diapause, the developmental cycle can be increased to enhance the application efficiency of $T$. dendrolimi. This is important for the mass production of Trichogramma on a commercial scale. Although diapause has been successfully manipulated, the molecular mechanism of diapause remains largely unknown.

We compared the gene expression profiles among different diapause stages of $T$. dendrolimi. Our results were either consistent with previous studies or provided additional information useful for understanding the mechanism of diapause. Novel genes, such as p53 and pdrg1 might be relevant to diapause or apoptosis processes. Further studies are needed to elucidate the functions of candidate genes during diapause.

Our results provide crucial information that would be useful for generating a diapause genetics toolkit and establishing a method for improving the practical application of $T$. dendrolimi in biological control programs. However, diapause is a complex process, so additional studies will be required to elucidate the genetics of this insect adaptation.

\section{Methods}

Insect culture

Adult $T$. dendrolimi were collected from a corn field in Yitong, Jilin Province, China $\left(125^{\circ} 11^{\prime} \mathrm{E}, 43^{\circ} 3^{\prime} \mathrm{N}\right)$ in 2015. Species identification was confirmed through the morphological characteristics of male genital capsules. A wasp population was maintained on the eggs of Antheraea pernyi (fresh eggs were dissected from the ovaries of female $A$. pernyi and were supplied in glass tubes to newly emerged $T$. dendrolimi for oviposition). The eggs were kept at $26{ }^{\circ} \mathrm{C} \pm 1{ }^{\circ} \mathrm{C}, 60 \% \pm 5 \%$ relative humidity $(\mathrm{RH})$ with a $16: 8 \mathrm{~h}(\mathrm{~L}: \mathrm{D})$ photoperiod.

\section{Diapause induction and termination}

Approximately 1000 eggs of $A$. pernyi were parasitized for $2 \mathrm{~h}$ by approximately $2500 \mathrm{~T}$. dendrolimi adults. The parasitized eggs were separated into two groups that received different treatments (Table 3). T. dendrolimi enteres diapause at the prepupa stage. Diapause prepupae and pupae after diapause were labeled Dpre and Dp, respectively. Non-diapause prepupae and non-diapause pupae were labeled NDpre and NDp. The methods for diapause induction and termination used in this study were based on those of Zhang et al. (2017) [18]. Specifically, diapause was induced by keeping $T$. dendrolimi at $12{ }^{\circ} \mathrm{C}$ and $60 \% \pm 5 \%$ relative humidity $(\mathrm{RH})$ with a $0: 24 \mathrm{~h}$ (L:D) photoperiod for $30 \mathrm{~d}$, and diapause was terminated by keeping $T$. dendrolimi at $3{ }^{\circ} \mathrm{C}$ and $60 \% \pm 5 \%$ relative humidity $(\mathrm{RH})$ with a 16: 8 -h light: dark (L: D) photoperiod for $70 \mathrm{~d}$ (Fig. S1; Table 3). Then the individuals 
Table 3 Different treatments for T. dendrolimi used in this study

\begin{tabular}{lllll}
\hline Groups $^{\mathbf{a}}$ & State & Treatment & Sampling Period & Sample Set \\
\hline 1 & Non-diapause & $26 \pm 1{ }^{\circ} \mathrm{C}, 60 \pm 5 \% \mathrm{RH}, 16: 8 \mathrm{~L}: \mathrm{D}$ & Prepupal stage & $\mathrm{NDpre}$ \\
& & $26 \pm 1{ }^{\circ} \mathrm{C}, 60 \pm 5 \% \mathrm{RH}, 16: 8 \mathrm{~L}: \mathrm{D}$ & Pupal stage & $\mathrm{NDp}$ \\
2 & $12 \pm 1{ }^{\circ} \mathrm{C}, 60 \pm 5 \% \mathrm{RH}, 0: 24 \mathrm{~L}: \mathrm{D}, 30 \mathrm{~d}$ & Prepupal stage & $\mathrm{Dpre}$ \\
& Diapause & $12 \pm 1{ }^{\circ} \mathrm{C}, 60 \pm 5 \% \mathrm{RH}, 0: 24 \mathrm{~L}: \mathrm{D}, 30 \mathrm{~d}$ & Pupal stage & \\
& $3 \pm 1{ }^{\circ} \mathrm{C}, 60 \pm 5 \% \mathrm{RH}, 0: 24 \mathrm{~L}: \mathrm{D}, 70 \mathrm{~d}$ & & \\
& $26 \pm 1{ }^{\circ} \mathrm{C}, 60 \pm 5 \% \mathrm{RH}, 16: 8 \mathrm{~L}: \mathrm{D}$, until pupal stage & & \\
& & &
\end{tabular}

${ }^{a}$ Groups 1 and 2 represent control and treatment, respectively

were kept at $26^{\circ} \mathrm{C} \pm 1{ }^{\circ} \mathrm{C}, 60 \% \pm 5 \%$ relative humidity (RH) with a 16:8 $\mathrm{h}(\mathrm{L}: \mathrm{D})$ photoperiod to develop.

\section{RNA isolation and qualification and library preparation}

Total RNA was extracted from four sample sets described above using TRIzol Reagent (Sigma Aldrich, St. Louis, MO, USA). Three replicates of four parasitized eggs were evaluated for each experiment. RNA degradation and contamination were monitored on $1 \%$ agarose gels. RNA purity, integrity, and concentration were checked using a NanoPhotometer ${ }^{\bullet}$ spectrophotometer (Implen, Westlake Village, CA, USA), RNA Nano 6000 Assay Kit of the Agilent Bioanalyzer 2100 system (Agilent Technologies, CA, USA), and Qubit ${ }^{\circ}$ RNA Assay Kit in a Qubit $^{\circ}$ 2.0 Flurometer (Life Technologies, CA, USA), respectively. A total of $1.5 \mu \mathrm{g}$ RNA per sample was used as input material for library preparation. Libraries used for sequencing were generated using the NEBNext ${ }^{\circ}$ UltraTM RNA Library Prep Kit for Illumina ${ }^{\circ}$ (NEB, USA) following manufacturer recommendations. Index codes were added to attribute sequences in each sample. Briefly, the mRNA was purified from the total RNA using poly-T oligo-attached magnetic beads. Firststrand cDNA was synthesized using random hexamer primers and M-MuLV Reverse Transcriptase (RNase H). Second-strand cDNA synthesis was subsequently performed using DNA Polymerase I and RNase $\mathrm{H}$. After adenylation of 3' ends of DNA fragments, a NEBNext Adaptor with hairpin loop structure was ligated to prepare for hybridization. To select cDNA fragments 250$300 \mathrm{bp}$ in length, the library fragments were purified with an AMPure XP system (Beckman Coulter, Brea, CA, USA). Then, $3 \mu$ l USER Enzyme (NEB, USA) was used with size-selected, adaptor-ligated cDNA at $37^{\circ} \mathrm{C}$ for $15 \mathrm{~min}$ followed by $5 \mathrm{~min}$ at $95^{\circ} \mathrm{C}$ before PCR. Then PCR was performed with Phusion High-Fidelity DNA polymerase, Universal PCR primers, and Index (X) Primer. PCR products were purified (AMPure XP system, Beckman Coulter, USA) and library quality was assessed on the Agilent Bioanalyzer 2100 system. The prepared libraries were then sequenced with the Illumina HiSeq platform (Novogene, China), and paired-end reads were generated. The RNA-seq raw reads were deposited as project number PRJNA597631 in the Sequence Read
Archive of the National Center for Biotechnology Information (NCBI). Three replicates were sequenced for each sample.

\section{De novo transcriptome assembly and functional annotation}

Raw data (raw reads) were processed using in-house Perl scripts. Clean reads were obtained after removing adaptor, ploy- $\mathrm{N}$, and low-quality reads. The Q20, Q30, GC-content, and sequence duplication level were measured. De novo transcriptome assembly was performed with Trinity 2.4.0 software ${ }^{[72]}$ with min_kmer_cov set to 25 and all other parameters at the default values [64]. All assembled transcripts were aligned using DIAMOND v0.8.22, NCBI blast 2.2.28+, HMMER 3.0, and KAAS, with the protein and nucleotide sequences in five public databases (NR, NT, Pfam, KEGG, and Swiss-Prot) with a threshold of $\mathrm{e}<0.00001$. Functional annotation of all the transcripts was carried out using Blast2GO v2.5 [65]. The Gene Ontology (GO) and Clusters of Orthologs Groups for Eukaryotic Complete Genomes (KOG) databases were used. Then according to the results of annotation, the transcripts were filtered to remove those annotated to the same functional genes, which were identified as unigenes.

\section{Identification of differential expression genes (DEGs) and functional classification}

Transcript expression levels were estimated by RSEM (RNA-Seq by Expectation-Maximization). A reference transcriptome was first generated by clustering all the samples unigenes i.e. Dpre, Dp, NDpre and NDp. Then the high-quality cleaned reads from each sample were aligned separately on a reference transcriptome using bowtie 2 with default parameters to obtain the read count of each sample [66]. Considering the influence of sequencing depth and gene length of fragments counts, the read counts were transferred into FPKM (Fragments Per Kilobase of transcript per million mapped reads), according to the following formula to measure the expression level of each assembled transcript sequence. $\mathrm{FPKM}=\frac{\text { total exon fragments }}{\text { mapped reads (millions) } \times \text { exon length }(\mathrm{kb})}$. DEGs between four conditions (Dpre vs. NDpre; Dpre vs. Dp; NDpre 
Table 4 Candidate genes and primers used for $\mathrm{QPCR}$ analysis

\begin{tabular}{|c|c|c|c|}
\hline Unigene ID & Gene name & Primer sequence & Amplicon size (bp) \\
\hline Cluster-6290.39995 & Heat shock protein 68 (HSP68) & $\begin{array}{l}\text { F: TTCTGCCGATGAGACGCTTGG } \\
\text { R: TGCCTTCACCGACACCGAGA }\end{array}$ & 104 \\
\hline Cluster-6290.35917 & Autophagy-related protein 2 (ATG2) & $\begin{array}{l}\text { F: TCTGGAGCAGTAGGTGGAGTGT } \\
\text { R: GCAGCCTCATGTCTGGCATCT }\end{array}$ & 137 \\
\hline Cluster-6290.40838 & Autophagy-related protein 9 (ATG9) & $\begin{array}{l}\text { F: TCGGCATCGTCAACTTCGTCCT } \\
\text { R: GCAGATAGAGGCGGCTGTAGGT }\end{array}$ & 144 \\
\hline Cluster-6290.35139 & Autophagy-related protein 13 (ATG13) & $\begin{array}{l}\text { F: CGCAGCAGCAACAACAACAACC } \\
\text { R: TGGTAGTGGTCGCCGATCTCTG }\end{array}$ & 111 \\
\hline Cluster-6290.30161 & cyclin D & $\begin{array}{l}\text { F: GCCACGAGCTGATCGAGGAGAT } \\
\text { R: GCTGTTGCTGTTGCTGCTGTTG }\end{array}$ & 102 \\
\hline Cluster-6290.19679 & Trehalose transporter (Tret) & $\begin{array}{l}\text { F: CGAGGCGAACATCCAGAAGGT } \\
\text { R: GGCAGCATCAGCATCGTCAC }\end{array}$ & 111 \\
\hline Cluster-6290.35295 & Trehalase (Tre) & $\begin{array}{l}\text { F: GCCGACATCACAACCGAAGACA } \\
\text { R: TCGTTCCAGAGCACCTCGTCAA }\end{array}$ & 173 \\
\hline Cluster-6290.42522 & Fatty acid synthase (FAS) & $\begin{array}{l}\text { F: CGACGAGAAGCAGTTCAAGGC } \\
\text { R: CGGACGAGAAGCAGACGAAGT }\end{array}$ & 116 \\
\hline Cluster-6290.41101 & lipid storage droplets surface-binding protein 2 (LSD2) & $\begin{array}{l}\text { F: GGCCGTGTCGAGGATCAACTAC } \\
\text { R: ACGAGCATCTCCAGGACGAAGG }\end{array}$ & 162 \\
\hline Cluster-6290.38030 & stearoyl-CoA desaturase 5 (SCD5) & $\begin{array}{l}\text { F: TGGAGTCGCTGGAGGAATACAC } \\
\text { R: ACGGGATCGGCATCGGTTC }\end{array}$ & 174 \\
\hline Internal control & Glyceraldehyde-3-phosphate dehydrogenase (GAPDH) & $\begin{array}{l}\text { F: CCAGCCACCTACGACGAGATCA } \\
\text { R: ACCACGAGATGAGCTTGACGAA }\end{array}$ & 187 \\
\hline
\end{tabular}

vs. NDp; Dp vs NDp) were identified using the DESeq $\mathrm{R}$ package. Prior to differential expression analysis, the read counts in each sample were normalized using the default normalization method within the DESeq package. The resulting $P$-values were adjusted using the Benjamini-Hochberg method to control the false discovery rate (FDR). Transcripts with an adjusted $P$-value less than 0.05 and a $\mid \log 2$ (fold change) | greater than 1 found by DESeq were considered as differentially expressed. A Venn diagram (http://bioinformatics.psb. ugent.be/beg/) was used to compare the four DEG lists.

Gene Ontology (GO) enrichment analysis of DEGs was implemented by the GOseq $\mathrm{R}$ package [67]. For GO enrichment analysis, corrected $P$-values less than 0.05 were considered as significantly enriched in DEGs. The top 10 biological processes involved in these four lists were also analyzed. According to the results of GO enrichment analysis, candidate genes related to different stages during diapause development in $T$. dendrolimi were selected and analyzed.

\section{Validation experiment by quantitative real-time PCR (qPCR) analysis}

Quantitative real-time PCR (qPCR) was performed on a qTOWER ${ }^{3} \mathrm{G}$ system (Analytikjena, Germany) using SYBR green PCR Master Mix (Tiangen, China). The thermal cycling conditions were as follows: one cycle of $95^{\circ} \mathrm{C}$ for $5 \mathrm{~min}, 40$ cycles of $95^{\circ} \mathrm{C}$ for $5 \mathrm{~s}$, and $60{ }^{\circ} \mathrm{C}$ for $15 \mathrm{~s}$, following the melt curve program. The GAPDH of
T. dendrolimi was selected as the internal standard to normalize the cDNA templates. Primers with product sizes of 100-200 bp were designed with Primer Premier 6 using the default settings. The selected candidate genes and corresponding primers are listed in Table 4. Three biological replicates were performed for each treatment with four technical replicates for each primer pair. The relative transcript expression levels among the different treatments were measured by the $2^{-\Delta \Delta C t}$ method. Statistical analysis of the qPCR was conducted in SPSS 19.0 (SPSS Inc., Chicago, IL, USA). Data are presented as the mean \pm standard error (SE). Significant differences between diapause and non-diapause were analyzed with independent sample $t$-tests.

\section{Supplementary Information}

The online version contains supplementary material available at https://doi. org/10.1186/s12864-020-07285-4.

\section{Additional file 1.}

\footnotetext{
Abbreviations

RNA-Seq: RNA sequencing; GO: Gene ontology; Dpre: Diapause prepupae; Dp: Pupae after diapause; NDpre: Non-diapause prepupae; NDp: Nondiapause pupae; NR: Non-redundant; DEGs: Differentially expressed genes; GAPDH: Glyceraldehyde phosphate dehydrogenase; tre: Trehalase; CYP450s: Cytochrome P450s; Mito: Mitochondrion; CNS: Central nervous system; hth: Homeobox protein homothorax; dll: Homeotic protein distal-less; exd: Extradenticle; foxo: Forkhead box protein O; foxe3: Forkhead box protein E3; foxd3: Forkhead box protein D3; PP2A: Protein phosphatase 2A; rpS11: Ribosomal protein S11; rpS5: Ribosomal protein S5; rpS3a: Ribosomal protein S3a; pdrg1: DNA damage-regulated gene 1; UDPGT: UDP-
} 
glucuronosyltransferase; GST: Glutathione-S-transferase; TAG: Triacylglycerol; KOG: Clusters of orthologs groups for eukaryotic complete genomes; FPKM: Fragments per kilobase million; RSEM: RNA-Seq by expectationMaximization; FDR: False discovery rate; qPCR: Quantitative real-time PCR

\section{Acknowledgments}

We thank LetPub (www.letpub.com) for its linguistic assistance during the preparation of this manuscript.

\section{Authors' contributions}

$J J Z, Z Z$, and CCR designed the research; XZ, JJZ and WMD preformed the research; $Z Z$ and $X Z$ analyzed the data; and $X Z$ and $Z Z$ wrote the manuscript. All authors read and approved the final manuscript.

\section{Funding}

This study was supported by the National Key R\&D Program of China (Grant No. 2017YFD0200400, 2019YFC1200504). The funder of No.2017YFD0200400 was JJZ and he designed the research and preformed part of the research. The funder of No.2019YFC1200504 was ZZ and he designed the research, analyzed the data and wrote the manuscript.

\section{Availability of data and materials}

The datasets generated and/or analysed during the current study are available in the Trichogramma dendrolimi Transcriptome repository (BioProject accession number PRJNA597631.). Illumina sequence reads have been deposited at NCBI SRA database under the following accession numbers (Dpre: Sample: SAMN13678825, Reads: SRR13060941, SRR13060940, SRR13060937; NDpre: Sample: SAMN13679415, Reads: SRR13060936, SRR13060935, SRR13060934; Dp: Sample: SAMN13679232, SRR13060933, SRR13060932, SRR13060931; NDp: Sample: SAMN13679414, Reads: SRR13060930, SRR13060939, SRR13060938).

\section{Ethics approval and consent to participate}

Not applicable.

\section{Consent for publication}

Not applicable.

\section{Competing interests}

The authors declare that they have no competing interests.

\section{Author details}

${ }^{1}$ Engineering Research Center of Natural Enemies, Institute of Biological Control, Jilin Agricultural University, Changchun 130118, China. ${ }^{2}$ State Key Laboratory of Integrated Management of Pest Insect and Rodents, Institute of Zoology, Chinese Academy of Sciences, Beijing 100101, China.

\section{Received: 12 February 2020 Accepted: 26 November 2020} Published online: 04 December 2020

\section{References}

1. Yuan XH, Song LW, Zhang JJ, Zang LS, Zhu L, Ruan CC, Sun GZ. Performance of four Chinese Trichogramma species as biocontrol agents of the rice striped stem borer, Chilo suppressalis, under various temperature and humidity regimes. J Pest Sci. 2012;85(4):497-504.

2. Tian JC, Wang ZC, Wang GR, Zhong LQ, Zheng XS, Xu HX, Zang LS, Lu ZX. The effects of temperature and host age on the fecundity of four Trichogramma species, egg parasitoids of the Cnaphalocrocis medinalis (Lepidoptera: Pyralidae). J Econ Entomol. 2017;110(3):949-53.

3. Huang J, Hua HQ, Wang LY, Zhang F, Li YX. Number of attacks by Trichogramma dendrolimi (Hymenoptera: Trichogrammatidae) affects the successful parasitism of Ostrinia furnacalis (Lepidoptera: Crambidae) eggs. Bull Entomol Res. 2017:107(6):812-9.

4. Zhang JJ, Ruan CC, Zang LS, Shao XW, Shi SS. Technological improvements for mass production of Trichogramma and current status of their applications for biological control on agricultural pests in China. Chin J Biol Control. 2015:31(5):638-46.

5. Pitcher SA, Hoffman MP, Gardner J, Wright MG, Kuhar TP. Cold storage of Trichogramma ostriniae reared on Sitotroga cerealella eggs. BioControl. 2002:47:525-35.
6. Ma CS, Chen YW. Effects of constant temperature, exposure period, and age on diapause induction in Trichogramma dendrolimi. Biol Control. 2006;36(3): 267-73

7. Rundle B, Thomson L, Hoffmann A. Effects of cold storage on field and laboratory performance of Trichogramma carverae (Hymenoptera: Trichogrammatidae) and the response of three Trichogramma spp. (T. carverae, T. nr. brassicae, and T. funiculatum) to cold. J Econ Entomol. 2004; 97(2):213-21.

8. Chen KW, Liu LZ, Fang CM, Huang SS. Effect of cold storage on massrearing population quality of Trichogrammatoidea bactrae. J S China Agric Univ. 2004;25(2):56-9.

9. Cira TM, Koch RL, Burkness EC, Hutchison WD, Venette RC. Effects of diapause on Halyomorpha halys (Hemiptera: Pentatomidae) cold tolerance. Environ Entomol. 2018;47(4):997-1004.

10. Zhang Q, Denlinger DL. Molecular characterization of heat shock protein 90 70 and 70 cognate cDNAs and their expression patterns during thermal stress and pupal diapause in the corn earworm. J Insect Physiol. 2010;56(2): 138-50.

11. Lin $\mathrm{X}, \mathrm{Xu}$ W. Hexokinase is a key regulator of energy metabolism and ROS activity in insect lifespan extension. Aging. 2016;8(2):245-58.

12. Zhang XS, Wang $T$, Lin XW, Denlinger $\mathrm{DL}, \mathrm{Xu}$ WH. Reactive oxygen species extend insect life span using components of the insulin-signaling pathway. PNAS. 2017;114(37):E7832-40.

13. Fenelon JC, Renfree MB. The history of the discovery of embryonic diapause in mammals. Biol Reprod. 2018:99(1):242-51.

14. Denlinger DL, Armbruster PA. Mosquito diapause. Annu Rev Entomol. 2014; 59:73-93.

15. Hand SC, Denlinger DL, Podrabsky JE, Roy R. Mechanisms of animal diapause: recent developments from nematodes, crustaceans, insects, and fish. Am J Physiol Regul Integr Comp Physiol. 2016;310(11):1193-211.

16. Ahmadi F, Moharramipour S, Mikani A. The effect of temperature and photoperiod on diapause induction in pupae of Scrobipalpa ocellatella (Lepidoptera: Gelechiidae). Environ Entomol. 2018;47(5):1314-22.

17. Ryan SF, Valella P, Thivierge G, Aardema ML, Scriber JM. The role of latitudinal, genetic and temperature variation in the induction of diapause of Papilio glaucus (Lepidoptera: Papilionidae). Insect Sci. 2018;25(2):328-36.

18. Zhang JJ, Desneux N, Benelli G, Zang LS, Du WM, Ruan CC. Geographic variation of diapause induction rates in Trichogramma dendrolimi (Hymenoptera: Trichogrammatidae) in China. J Econ Entomol. 2017;110(2):386-91.

19. Takano Y, Ullah MS, Gotoh T. Effect of temperature on diapause termination and post-diapause development in Eotetranychus smithi (Acari: Tetranychidae). Exp Appl Acarol. 2017;73(3-4):353-63.

20. Hiroyoshi S, Reddy GVP, Mitsuhashi J. Effects of photoperiod, temperature and aging on adult diapause termination and post-diapause development in female Asian comma butterflies, Polygonia caureum Linnaeus (Lepidoptera: Nymphalidae). J Comp Physiol A. 2018;204(9-10):849-58.

21. Chen $\mathrm{W}, \mathrm{Xu} \mathrm{WH}$. Wnt/beta-catenin signaling regulates Helicoverpa armigera pupal development by up-regulating c-Myc and AP-4. Insect Biochem Mol Biol. 2014:53:44-53.

22. Sim C, Kang DS, Kim S, Bai X, Denlinger DL. Identification of FOXO targets that generate diverse features of the diapause phenotype in the mosquito Culex pipiens. PNAS. 2015;112(12):3811-6.

23. Lin XW. Tang L, Yang J, Xu WH. HIF-1 regulates insect lifespan extension by inhibiting c-Myc-TFAM signaling and mitochondrial biogenesis. Biochim Biophys Acta. 2016;1863(11):2594-603.

24. Li HY, Wang T, Yang YP, Geng SL, Xu WH. TGF- $\beta$ signaling regulates $p-A k t$ levels via PP2A during diapause entry in the cotton bollworm, Helicoverpa armigera. Insect Biochem Mol Biol. 2017;87:165-73.

25. Post S, Liao S, Yamamoto R, Veenstra JA, Nassel DR, Tatar M. Drosophila insulin-like peptide dilp1 increases lifespan and glucagon-like Akh expression epistatic to dilp2. Aging Cell. 2018;18(1):e12863.

26. Song Z, Yang YP, Xu WH. PTEN expression responds to transcription facto POU and regulates p-AKT levels during diapause initiation in the cotton bollworm, Helicoverpa armigera. Insect Biochem Mol Biol. 2018;100:48-58.

27. Zhang JJ, Zhang X, Zang LS, Du WM, Hou YY, Ruan CC, Desneux N. Advantages of diapause in Trichogramma dendrolimi mass production on eggs of the Chinese silkworm, Antheraea pernyi. Pest Manag Sci. 2018;74(4): 959-65.

28. Antony B, Johny J, Abdelazim MM, Jakse J, Al-Saleh MA, Pain A. Global transcriptome profiling and functional analysis reveal that tissue-specific constitutive overexpression of cytochrome P450s confers tolerance to 
imidacloprid in palm weevils in date palm fields. BMC Genomics. 2019;20(1): $1-23$.

29. Xu N, Sun XH, Liu ZH, Xu Y, Sun Y, Zhou D, Shen B, Zhu CL. Identification and classification of differentially expressed genes in pyrethroid-resistant Culex pipiens pallens. Mol Gen Genomics. 2019;294(4):861-73.

30. Peterson B, Sanko TJ, Bezuidenhout CC, van den Berg J. Transcriptome and differentially expressed genes of Busseola fusca (Lepidoptera: Noctuidae) larvae challenged with Cry1Ab toxin. Gene. 2019;710:387-98.

31. Li Z, Yu T, Chen Y, Heerman M, He J, Huang J, Nie H, Su S. Brain transcriptome of honey bees (Apis mellifera) exhibiting impaired olfactory learning induced by a sublethal dose of imidacloprid. Pestic Biochem Physiol. 2019;156:36-43.

32. Govaere L, Morin MD, Frigault JJ, Boquel S, Cohen A, Lamarre SG, Morin PJ. Transcriptome and proteome analyses to investigate the molecular underpinnings of cold response in the Colorado potato beetle, Leptinotarsa decemlineata. Cryobiology. 2019;88:54-63.

33. Xiong $Y$, Liu XQ, Xiao PA, Tang GH, Liu SH, Lou BH, Wang JJ, Jiang HB. Comparative transcriptome analysis reveals differentially expressed genes in the Asian citrus psyllid (Diaphorina citri) upon heat shock. Comp Biochem Physiol Part D Genomics Proteomics. 2019;30:256-61.

34. Wu Z, Kang C, Qu M, Chen J, Chen M, Bin S, Lin J. Candidates for chemosensory genes identified in the Chinese citrus fly, Bactrocera minax, through a transcriptomic analysis. BMC Genomics. 2019;20(1):646-60.

35. Hao K, Jarwar AR, Ullah H, Tu X, Nong X, Zhang Z. Transcriptome sequencing reveals potential mechanisms of the maternal effect on egg diapause induction of Locusta migratoria. Int J Mol Sci. 2019;20(8): 1974-93.

36. Kostal V, Simunkova P, Kobelkova A, Shimada K. Cell cycle arrest as a hallmark of insect diapause: changes in gene transcription during diapause induction in the drosophilid fly, Chymomyza Costata. Insect Biochem Mol Biol. 2009;39(12):875-83.

37. Sim C, Denlinger DL. Insulin signaling and FOXO regulate the overwintering diapause of the mosquito Culex pipiens. PNAS. 2008;105(18):6777-81.

38. Tian K, Xu WH. High expression of PP2A-Aa is associated with diapause induction during the photoperiod-sensitive stage of the cotton bollworm, Helicoverpa armigera. J Insect Physiol. 2013;59(6):588-94.

39. Chaillou T, Kirby TJ, McCarthy JJ. Ribosome biogenesis: emerging evidence for a central role in the regulation of skeletal muscle mass. J Cell Physiol. 2014;229(11):1584-94.

40. Reynolds JA, Poelchau MF, Rahman Z, Armbruster PA, Denlinger DL. Transcript profiling reveals mechanisms for lipid conservation during diapause in the mosquito, Aedes albopictus. J Insect Physiol. 2012;58(7):966-73.

41. Batz ZA, Armbruster PA. Diapause-associated changes in the lipid and metabolite profiles of the Asian tiger mosquito, Aedes albopictus. J Exp Biol. 2018;221(Pt 24):jeb189480.

42. Hannemann F, Bichet A, Ewen KM, Bernhardt R. Cytochrome P450 systems-biological variations of electron transport chains. Biochim Biophys Acta. 2007;1770(3):330-44.

43. Yin $\mathrm{CL}$, Ye XH, Chen MY, Mei Y. M XH, Li F: evolution analysis of cytochrome P450 gene family in parasitoid wasps. Chin J Biol Control. 2019;35(3):335-42.

44. Ziniel PD, Karumudi B, Barnard AH, Fisher EM, Thatcher GR, Podust LM, Williams DL. The Schistosoma mansoni cytochrome P450 (CYP3050A1) is essential for worm survival and egg development. PLoS Negl Trop Dis. 2015;9(12):e0004279.

45. Qiu Y, Tittiger C, Thomas C, Goff G, Young S, Wajnberg E, Fricaux T, Taquet $\mathrm{N}$, Blomquist G, Feyereisen R. An insect-specific P450 oxidative decarbonylase for cuticular hydrocarbon biosynthesis. PNAS. 2012;109: 14858-63.

46. Chen DF, Lin C, Wang HL, Zhang L, Dai L, Jia SN, Zhou R, Li R, Yang JS, Yang F, et al. An La-related protein controls cell cycle arrest by nuclear retrograde transport of tRNAs during diapause formation in Artemia. BMC Biol. 2016;14(16):1-13.

47. Chen L, Barnett RE, Horstmann M, Bamberger V, Heberle L, Krebs N, Colbourne JK, Gomez R, Weiss LC. Mitotic activity patterns and cytoskeletal changes throughout the progression of diapause developmental program in Daphnia. BMC Cell Biol. 2018;19(1):30-43.

48. Shimizu Y, Mukai A, Goto SG. Cell cycle arrest in the jewel wasp Nasonia vitripennis in larval diapause. J Insect Physiol. 2018;106(Pt 2):147-52.

49. Smith FW, Jockusch EL. Hox genes require homothorax and extradenticle for body wall identity specification but not for appendage identity specification during metamorphosis of Tribolium castaneum. Dev Biol. 2014; 395(1):182-97.

50. Pai CY, Kuo TS, Jaw TJ, Kurant E, Sun YH. The Homothorax homeoprotein activates the nuclear localization of another homeoprotein, Extradenticle, and suppresses eye development in Drosophila. Genes Dev. 1998;12(3):435-46.

51. Vachon G, Cohen B, Pfeifle C, McGuffin ME, Botas J, Cohen SM. Homeotic genes of the Bithorax complex repress limb development in the abdomen of the Drosophila embryo through the target gene distal-less. Cell. 1992; 71(3):437-50.

52. Ikeda K, Ookawara S, Sato S, Ando ZI, Kageyama R, Kawakami K. Six 1 is essential for early neurogenesis in the development of olfactory epithelium. Dev Biol. 2007;311(1):1-68.

53. Wlodarchak N, Xing Y. PP2A as a master regulator of the cell cycle. Crit Rev Biochem Mol Biol. 2016;51(3):162-84.

54. Bánréti Á, Lukácsovich T, Csikós G, Erdélyi M, Sass M. PP2A regulates autophagy in two alternative ways in Drosophila. Autophagy. 2012;8(4):623-36.

55. Altiok $\mathrm{S}, \mathrm{Xu}$ M, Spiegelman BM. PPARgamma induces cell cycle withdrawal: inhibition of E2F/DP DNA-binding activity via down-regulation of PP2A. Genes Dev. 1997;11(15):1987-98.

56. Kolupaeva V, Daempfling L, Basilico C. The B55a regulatory subunit of protein phosphatase 2A mediates fibroblast growth factor-induced p107 dephosphorylation and growth arrest in chondrocytes. Mol Cell Biol. 2013; 33(15):2865-78

57. Tang Y, Berlind J, Mavila N. Inhibition of CREB binding protein-beta-catenin signaling down regulates CD133 expression and activates PP2A-PTEN signaling in tumor initiating liver cancer cells. Cell Commun Signal. 2018; 16(1):9-21.

58. Kurata S, Koga K, Sakaguchi B. Nueleolar size in parallel with ribosomal RNA synthesis at diapause termination in the eggs of Bombyx mori. Chromosoma. 1978;68:313-7.

59. Gong J, Tian S, Zhou X, Yang H, Zhu Y, Hou Y. Transcriptional response of silkworm (Bombyx mori) eggs to O2 or HCl treatment. Int J Mol Sci. 2016; 17(12):1838-57.

60. Kim M, Sim C, Denlinger DL. RNA interference directed against ribosomal protein S3a suggests a link between this gene and arrested ovarian development during adult diapause in Culex pipiens. Insect Mol Biol. 2010; 19(1):27-33.

61. Levine A. p53, the cellular gatekeeper for growth and division. Cell. 1997;88: $323-31$.

62. Zhang W, Yao F, Zhang H, Li N, Zou X, Sui L, Hou L. The potential roles of the apoptosis-related protein PDRG1 in diapause embryo restarting of Artemia sinica. Int J Mol Sci. 2018;19(1):126-44.

63. Santos PKF, de Souza AN, Francoso E, Zuntini AR, Arias MC. Diapause in a tropical oil-collecting bee: molecular basis unveiled by RNA-Seq. BMC Genomics. 2018;19(1):305-18.

64. Grabherr MG, Haas BJ, Yassour M, Levin JZ, Thompson DA, Amit I, Adiconis X, Fan L, Raychowdhury R, Zeng Q, et al. Full-length transcriptome assembly from RNA-Seq data without a reference genome. Nat Biotechnol. 2011;29(7): $644-52$.

65. Gotz S, Garcia-Gomez JM, Terol J, Williams TD, Nagaraj SH, Nueda MJ, Robles M, Talon M, Dopazo J, Conesa A. High-throughput functional annotation and data mining with the Blast2GO suite. Nucleic Acids Res. 2008;36(10):3420-35.

66. Li B, Dewey C. RSEM: accurate transcript quantification from RNA-Seq data with or without a reference genome. BMC Bioinformatics. 2011;12:16.

67. Young MD, Wakefield MJ, Smyth GK, Oshlack A. Gene ontology analysis for RNA-seq: accounting for selection bias. Genome Biol. 2010;11.

\section{Publisher's Note}

Springer Nature remains neutral with regard to jurisdictional claims in published maps and institutional affiliations. 